\title{
The Impact of Brexit on the Careers of EUI Law Graduates
}

Marise Cremona \& Angelos Dimopoulos

\begin{abstract}
This paper raises some questions about the possible impact of the UK leaving the European Union on the career pathways of mobile and internationally-oriented $\mathrm{PhD}$ graduates interested in an academic career in law, with particular reference to the specific case of the European University Institute (EUI). It first addresses some of the reasons for the popularity of the UK academic job market as a destination for EUI law graduates and then considers the potential impact of Brexit on these factors. While a number of factors have made the UK an attractive market for these highly mobile young scholars, their mobility means that should the balance shift, other countries may replace the UK as top choice.
\end{abstract}

\section{Key words}

Brexit; early-career academics; UK universities; European University Institute / EUI

\section{Introduction}

In this short paper we aim to raise some questions about the possible impact of the UK leaving the European Union on the career pathways of mobile and internationally-oriented PhD graduates interested in an academic career in law. We do this with particular reference to the specific case of the European University Institute (EUI), in part because we have both spent time there as well as in UK academia, ${ }^{1}$ but also because of the EUI's distinctive characteristics as an institution whose central raison d'être is to produce excellent $\mathrm{PhD}$ graduates in the social sciences and humanities, bringing together doctoral (and post-doctoral) researchers from across Europe.

The EUI produces a relatively large group of PhD law graduates annually (174 in the five years 2012$2017^{2}$ ). They come from all over Europe (the EUI has 23 Member States as well as association arrangements with other European countries such as Norway, Iceland and Switzerland), together with a few from beyond Europe. A significant proportion of these graduates follow an academic career path: $55 \%$ of EUI law graduates, according to the most recent survey. ${ }^{3}$ The EUI's Law Department has a particular expertise and research emphasis in international, transnational and European (public and private) law.

EUI PhD researchers are funded by national grants and its $\mathrm{PhD}$ is recognised by all its Member States; nevertheless, as an international organisation it sits to some extent outside all national

\footnotetext{
${ }^{1}$ Marise Cremona was a professor in the law department of the EUI from 2006 until 2017, and is now Emeritus Professor; before joining the EUI she was at the Centre for Commercial Law Studies, QMUL. Angelos Dimopoulos studied for his PhD at the EUI between 2006 and 2010 and has since worked in the Netherlands and the UK (QMUL).

2 The statistics relating to the EUI are taken from the latest self-evaluation report of the EUI's Law Department 2012-2017, published February 2018 (on file with the authors).

${ }^{3}$ Law Department Self-Evaluation Report 2012-2017, note 2. For the report of a survey conducted in 2012 by the EUI's Academic Careers Observatory into the job market experience of EUI doctoral and post-doctoral researchers, see Academic Careers Observatory, Job Market Survey Report (European University Institute, 2012) <https://www.eui.eu/Documents/MWP/AcademicCareers/Workshop/ACOJobMarketSurveyReport.pdf> accessed 9 January 2019.
} 
systems. EUI graduates have thus already made a conscious decision to move away from their national academic system to do their PhD at the EUI, and although some do return to their home country after their doctorate, many do not. Their working language is English, the teaching medium is English, and although there is no requirement to this effect the vast majority of EUI PhDs are in English. ${ }^{4}$ These graduates are therefore inherently more mobile and are prepared to consider - and perhaps have a preference for - a position in a country other than their own. They tend to regard the whole of the EU as their potential job market. ${ }^{5}$ And among EU countries, the UK has been an especially favoured destination.

In what follows we will first briefly explain the popularity of the UK academic job market as a destination for EUI law graduates and then consider the potential impact of Brexit on these factors. While a number of factors have made the UK an attractive market for these highly mobile young scholars, their mobility means that should the balance shift, other countries may replace the UK as top choice.

\section{Explaining the popularity of the UK}

The UK currently attracts a significant proportion of internationally-mobile young academics. Among EUI law graduates who go on to academic jobs, more than $20 \%$ take up academic positions in the UK. The UK is in the top position alongside the Netherlands, with significantly more than any other country. ${ }^{6}$ In addition - based on anecdotal evidence - many graduates who start their academic career in the Netherlands go on to a position in the UK.

The reasons for the popularity of the UK market are diverse, and based on factors affecting both demand and supply. It is an expanding market: the number of academic staff has grown steadily since 2010 and student numbers have also risen. ${ }^{7}$ Although it is relatively mobile and the number of temporary contracts is increasing, it still offers higher job security than many European competitors: in Germany, for example, $85 \%$ of staff not at professorial level are on temporary contracts. ${ }^{8}$ Some national markets are still not open to those who have not followed a traditional national academic training: in Spain, for example, $95 \%$ of professors obtaining new positions already held a position in the same institution. ${ }^{9}$ The UK market is perceived to be - and still is, relatively-speaking - more

\footnotetext{
${ }^{4}$ For example, out of 174 theses successfully defended in the EUI Law Department between 2012 and 2017, 9 were in French and 1 in Spanish; the rest were in English: Law Department Self-Evaluation Report 2012-2017, note 2 .

${ }^{5}$ This is particularly true of lawyers; economists and to some extent political scientists will also consider the US job market.

${ }^{6}$ The top four destinations among the 2012-2017 EUI graduates were the UK (18), The Netherlands (18), Italy (12) and Germany (10; Law Department Self-Evaluation Report 2012-2017, note 2.

${ }^{7}$ On staff numbers, see Higher Education Statistics Agency (HESA), 'Staff numbers and characteristics', https://www.hesa.ac.uk/data-and-analysis/staff, accessed 12 February 2019. On student numbers, see HESA, 'First year higher education (HE) student enrolments by level of study, Academic years 2008/09 to 2017/18', https://www.hesa.ac.uk/data-and-analysis/sb252/figure-1, accessed 12 February 2019.

8 J Grove, 'Academic fixed-term jobs changes in Germany split opinion', Times Higher Education, 6 April 2017, citing an analysis by German Rectors' Conference (the Hochschulrektorenkonferenz), $<$ https://www.timeshighereducation.com/unijobs/article/academic-fixed-term-jobs-changes-germany-splitopinion/> accessed 9 January 2019.

9 P Álvarez and M Marín Yarza, 'La endogamia alcanza al 73\% de los docents', El País, 30 November 2014. <http://politica.elpais.com/politica/2014/11/28/actualidad/1417196515_775495.html> accessed 9 January 2019.
} 
open to non-UK graduates, not only in terms of initial entry but also in career progression. ${ }^{10} \mathrm{UK}$ academia offers comparatively better career development opportunities, especially for early and mid-career academics. To this we may add the low language barrier, given the predominance of English as the lingua franca of scholarship; and the UK's very strong reputation in EU and international law, in itself a draw for those working in those fields.

The UK thus remains a popular destination despite research findings that UK academics suffer from overwork, high stress and a managerial culture. ${ }^{11}$

\section{Brexit and its impact on mobile EU academics}

EU nationals form a significant proportion of the academic staff in Higher Education in the UK: in $2017,19 \%$ of academic staff in UK universities (24\% in Russell Group institutions) were EU nationals, an increase from $12 \%$ (15\% in Russell Group institutions) in $2004 .{ }^{12}$ Since the referendum in 2016 the overall percentage of EU academics in UK universities has ceased growing but has not (yet) dropped significantly; however, there has been a slight decrease in the percentage of young, entry-level academics (aged 34 and under) from $26.99 \%$ to $26.61 \%$, since $2016 .{ }^{13}$

Some of the factors which were identified above as making the UK an attractive first destination for young mobile academics will not be directly or immediately impacted by Brexit: the language, career opportunities for entry and mid-level academics, and the openness of the market are likely to remain stable. Barriers to entry to non-UK academic markets in Europe remain high. Nevertheless, a number of factors may make the UK market less attractive. Some of these are structural to that market, and some personal to the individual academic deciding on her options.

The structural impacts include the following.

First, Brexit will have an impact on the competitive position of UK universities. Rising fees as EU students are charged full overseas student rates and lose access to student loan schemes, alongside the increasing international competitiveness of alternative programmes within the EU (such as those

\footnotetext{
10 'Senior figures within HEls are less concerned about employing international staff per se than about ensuring that UK universities remain competitive and can recruit the best possible staff.' M Gustafsson \& T Borgar Hansen, POCARIM: Mapping the Population, Careers, Mobilities and Impacts of Advanced Research Degree Graduates in Social Sciences and Humanities (Oxford Research, 2012) 8, citing D Mills, A Jepson, T Coxon, M Easterby-Smith, P Hawkins, \& J Spencer, Demographic Review of the UK Social Sciences (ESRC, 2006).

${ }^{11}$ See eg J Grove, 'THE University Workplace Survey 2016: results and analysis', Times Higher Education, 4 February 2016, <https://www.timeshighereducation.com/features/university-workplace-survey-2016-resultsand-analysis> accessed 9 January 2019.

${ }^{12} \mathrm{G}$ Marini 'Are EU university academics leaving the UK because of Brexit?' Centre for Global Higher Education, Policy Briefing No.7, 30 May 2018. <https://www.researchcghe.org/perch/resources/publications/pb7.pdf> accessed 9 January 2019.

${ }^{13} \mathrm{G}$ Marini 'Are EU university academics leaving the UK because of Brexit?' Centre for Global Higher Education, Policy Briefing No.7, 30 May 2018. <https://www.researchcghe.org/perch/resources/publications/pb7.pdf> accessed 9 January 2019. On the reduction in applications for positions and fellowships from early-career academics from the EU, see Professor Michael Arthur and others, oral evidence to the House of Commons Committee on Exiting the EU (The progress of the UK's negotiations on EU withdrawal, HC 372) 16 May 2018, Q1717 and Q1718. <http://data.parliament.uk/writtenevidence/committeeevidence.svc/evidencedocument/exiting-theeuropean-union-committee/the-progress-of-the-uks-negotiations-on-eu-withdrawal/oral/83138.html> accessed 9 January 2019.
} 
offered by universities in the Netherlands, Sweden and Denmark) are likely to affect student numbers and the financial position of universities. ${ }^{14}$ In addition, many research-led universities will suffer from losing access to EU research funding. ${ }^{15}$ The growth of the sector may slow, resulting in fewer job openings and a negative impact on career prospects for younger academics.

Second, questions arise over the future of EU law in UK law schools, and thus the demand for teachers, the ability of UK universities to retain its currently very high reputation in EU law, and the medium / longer-term attractiveness of the UK as a place to study and do research in EU law.

Third, the openness of the UK academic market is likely to be adversely affected by the government's proposed immigration policy. At the time of writing this is still at proposal stage, ${ }^{16}$ but the indications are that a cap on high-skilled workers and / or the proposed minimum salary threshold for a Tier 2 visa ( $£ 30,000$ p.a.), as well as the increased costs associated with employing EU / EEA nationals will represent a significant change, especially for entry-level posts where recruitment is likely to be below the minimum salary threshold.

Fourth, and related to this, there are worrying signs that it is becoming increasingly difficult for nonEU scholars to visit UK academic events and conferences, due to visa restrictions. After Brexit, visitors from EU / EEA countries may be subject to the same controls (whether they will or not is still unclear). Apart from the impoverishment of UK academic life that this represents at an individual level, organisers of international academic events have started to argue that the UK should no longer be considered a suitable venue, since even highly eminent academics may be refused entry. ${ }^{17}$

These factors suggest that UK universities will be at risk of falling from their current very high position in world rankings, and as a result losing some of their attraction as top-ranking places to work for the best young scholars. ${ }^{18}$

\footnotetext{
${ }^{14} \mathrm{EU}$ students represent $6 \%$ of all students at UK universities. According to a recent report, the number of EU students starting postgraduate taught courses fell by $5 \%$, and the number of EU postgraduate researcher registrations fell by $9 \%$ in 2018-19 as compared with 2017-18. J Grove, 'Postgraduate numbers plummet amid fears for no-deal Brexit', Times Higher Education, 4 January 2019.

<https://www.timeshighereducation.com/news/postgraduate-numbers-plummet-amid-fears-no-deal-brexit> accessed 9 January 2019. Note however that according to HESA, since 2012/13 the number of first year students from China each year has exceeded the number from all EU countries combined: HESA, 'First year non-UK domicile students by domicile, Academic years 2006/07 to 2017/18', https://www.hesa.ac.uk/dataand-analysis/students/where-from, accessed 12 February 2019.

${ }^{15}$ Under Articles 137 and 138 of the draft Withdrawal Agreement, the UK will continue to participate in research programmes under the 2014-2020 financial framework until 2020. A future agreement may be concluded between the UK and the EU allowing the former to contribute to and participate in future EUfunded research programmes: see draft Political Declaration setting out the framework for the future relationship between the European Union and the United Kingdom, Council doc. XT 21095/18, 22 November 2018, para 11. However, such an agreement and its terms are far from certain. See further British Academy Briefing, 'Association with European Union Framework Programmes for Research \& Innovation: Challenges and Opportunities', December 2018, https://www.thebritishacademy.ac.uk/sites/default/files/EU-FrameworkBritish-Academy-Brexit-Briefing.pdf, accessed 12 February 2019.

${ }^{16}$ British Government White Paper, 'The UK's future skills-based immigration system', December 2018, Cm 9722.

${ }^{17}$ See eg A Fazackerley, 'University conferences at risk as academic speakers refused UK visas' The Guardian, 26 September 2017; M Weaver, 'WHO voices alarm as academics denied visas to visit UK conference' The Guardian, 9 October 2018.

18 'In 20 years' time, instead of being second in the world to the United States of America, I'm worried that we will be 20th or so. We will sit there asking, "How did that happen?", and part of it will be this insidious onset of inability to recruit the world's greatest talent.' Professor Michael Arthur, oral evidence to the House of
} 
At the level of the individual junior academic looking for a first or second position, a number of negative factors may impact a decision to target the UK job market.

First, UK universities have until now had a very good track record in securing EU research funding. ${ }^{19}$ Access to such funding is put into question by the type of future relationship currently being considered by the UK government, and even were it included in a future agreement, it would not be on the same basis as an EU Member State. For example, the leadership role played by UK universities in collaborative research bids will change. ${ }^{20}$ The ability to attract research funds, as well as offering increased research opportunities, has become an important step in the career progression of academics, and especially early stage researchers. Exclusion from (for example) ERC Starting Grants will have a negative impact. ${ }^{21}$ Even if the UK government were in the long-term to replace the EU funding currently enjoyed by UK-based academics, ERC and other EU research funding such as the Marie Skłodowska-Curie Fellowships have acquired a reputational cachet which will be difficult to replicate.

Second (and related), exclusion from - or more limited access to - transnational research networks arising out of research projects will negatively impact the careers of young academics seeking to establish a place in the community of scholars working in the field. Of course, Brexit will not mean that the UK is cut off from collaborative research networks, but it is likely to be more difficult to establish them across borders.

Third, barriers to mobility would re-emerge. For young, internationally-minded scholars ease of mobility is an important factor. The loss of the benefits that EU-national workers currently enjoy in the UK - including, importantly, the rights of family members and the corresponding lack of security - are likely to be an important disincentive to join UK academia. ${ }^{22}$ While the rights of those currently working in the UK may be partially preserved (assuming the Withdrawal Agreement is ratified), this will be dependent on the individual's continued residence in the UK; an exit decision would risk becoming permanent and the temporary mobility of academic staff would be more difficult: periods of study leave spent outside the UK, for example, may prevent the acquisition of 'settled status'.

It should be added that the above is postulated on the assumption that Brexit takes places within the framework of a Withdrawal Agreement and a transitional period, which would protect the rights

Commons Committee on Exiting the EU, note 13, Q1705.

<http://data.parliament.uk/writtenevidence/committeeevidence.svc/evidencedocument/exiting-theeuropean-union-committee/the-progress-of-the-uks-negotiations-on-eu-withdrawal/oral/83138.html> accessed 9 January 2019.

${ }^{19}$ The Royal Society, 'UK research and the European Union The role of the EU in funding UK research', 2015, https://royalsociety.org/topics-policy/projects/uk-research-and-european-union/role-of-EU-in-funding-UKresearch/how-much-funding-does-uk-get-in-comparison-with-other-countries/, accessed 12 February 2019.

${ }^{20}$ This is already happening: see evidence by Dr Sarah Main and Professor Michael Arthur to the Committee on Exiting the EU, note 13, Q1708-1709.

${ }^{21}$ In 2018, 50 out of 67 ERC Starter Grants won by the UK were awarded to non-UK nationals. European Research Council, 'ERC Starting Grants 2018 Outcome: Indicative statistics', 6. <https://erc.europa.eu/sites/default/files/document/file/erc_2018_stg_statistics.pdf> accessed 9 January 2019.

22 'There is a ready supply of talent that comes to this country at PhD student stage or early career researcher stage, many of whom stay on and make their careers here. They have been able to do that in the full knowledge that, as European citizens, they have full rights in this country. What does that future look like for them? If you were one of those individuals, would you make the decision to leave your home country and come to the UK if there was uncertainty?' Professor Michael Arthur, oral evidence to the House of Commons Committee on Exiting the EU, note 13, Q1703. 
of EU27 nationals currently working in the UK (and UK nationals working in the EU27). Should the UK exit the EU without a Withdrawal Agreement, the position would be highly unpredictable, the exodus of EU27 academics from the UK likely to be much higher, and the impact on UK universities very severe.

EUI law graduates, as we have argued, may be said to exemplify internationally mobile early-career academics, and as such are likely to be impacted by Brexit in the ways we have suggested here. However, in the discussion so far we have focused on the position of EU27 academics working in the UK. Brexit, of course, also affects the career prospects of young UK academics, including those who have taken, or will take, their PhD at the EUI.

The EUI is an international organisation, institutionally separate from the EU. Just as not all EU Member States are EUI members, ${ }^{23}$ Brexit does not imply that the UK should also withdraw from the EUI, and we must hope that it would not choose to do so, or - should it decide to withdraw - that it will enter into an agreement with the EUI enabling it to continue to fund doctorates there. ${ }^{24}$ The EUI law graduates impacted by Brexit may well therefore include researchers in receipt of UK PhD grants. Those EUI graduates who are UK nationals (or, better, UK resident non-EU nationals ${ }^{25}$ ) will be more seriously impacted than EUI graduates from the EU27. The latter may, as argued above, find that the UK academic market is less attractive and less accessible. EUI graduates from the UK, however, will experience increased obstacles to mobility across the EU-wide academic job market as, of course, will UK nationals who complete their academic training in UK universities. Even those who start work in an EU27 university before Brexit or during the transitional period will find their intra-EU mobility - their ability to move to another EU Member State - restricted. The precise terms of intra-EU mobility will depend on the terms of the EU-UK future agreement, but on the assumption that it does not include freedom of movement for people, opportunities for work within EU universities will depend on the immigration policies of individual Member States, and UK academics will not have any automatic rights.

We are thus likely to see a greater proportion of EUI PhD graduates who are UK nationals returning to work in the UK, and staying there. As already mentioned, short-term mobility will be more difficult and UK early career academics will have a less 'European' career pattern. The impact will be a personal one on the individual academic, but will also affect the culture of UK law schools, insofar as we may see not only fewer members of staff from elsewhere in Europe but also UK staff with less experience of working outside the UK.

\section{Conclusion - the impact of Brexit mitigation strategies}

Unsurprisingly, UK universities are putting in place strategies to attempt to mitigate some of the likely impacts outlined above. However speculative these predictions may be, some impacts are already being felt and any Brexit outcome will only increase them. Some of these strategies involve putting pressure on government to treat continued research collaboration and involvement in EU-

\footnotetext{
${ }^{23}$ The EUI currently has 23 members.

${ }^{24}$ At the time of writing, a draft Statutory Instrument has been published on the UK's membership of the EUI, which presupposes that the UK will 'automatically' withdraw from the EUI as a result of Brexit (The European University Institute (EU Exit) Regulations 2019, published 7 February 2019); this does not, however, follow from the text of the EUI Convention and withdrawal would certainly require negotiation of withdrawal terms with the other EUI Members.

${ }^{25}$ Since the UK grant criteria are residence-based, not all recipients of the UK grants are UK nationals.
} 
funded research programmes as a priority, as well as putting in place provision to ease researcher and student mobility. These initiatives fall outside the scope of this short paper. However, one strategy should be mentioned here, although its potential impacts are even more speculative. A number of UK universities have been preparing for Brexit by building institutional partnerships with other EU universities. ${ }^{26}$ To take only a couple of examples, the University of Glasgow has established a joint research centre with Leuphana University of Lüneburg in Germany; ${ }^{27}$ the University of Warwick has a partnership with the University of Paris Seine and Vrije Universiteit Brussels; ${ }^{28}$ and Oxford University has agreed a partnership with four universities in Berlin (the Freie Universität Berlin, Humboldt-Universität zu Berlin, Technische Universität Berlin, and the Charité Universitätsmedizin Berlin). ${ }^{29}$ These partnerships, it is planned, will include joint teaching and research programmes and will allow the UK universities some continued access to EU research funds. The medium / long-term implications of these initiatives (of which we are likely to see more) are difficult to assess, but three predictions can be made which are relevant to the subject of this paper.

First, these partnerships may well encourage inter-institutional staff (and student) mobility, somewhat off-setting the impact of Brexit. This would be a positive outcome, but the nature of that mobility will be different: it would be academic mobility within defined groups of universities and research institutions, and thus more institutionally managed than simply an individual academic's life-choice.

Second, the institutional links are institution-wide, not faculty, department or research-group led. They are designed to facilitate access to research funding. As a result, UK-based academics planning research collaborations will find themselves encouraged - or even constrained, to ensure eligibility to work with colleagues in their university's partner institutions, rather than choosing and building their own networks. These two consequences would operate together to increase collaboration and mobility within the partnership, while rendering such interchange more structural and less individual.

Third, closer partnerships between UK universities and universities in the EU27 are likely to impact those EU27 universities as well, with potential longer-term implications for the higher education culture in EU Member States. To some extent this would build on and encourage existing trends:

\footnotetext{
${ }^{26}$ Quirin Schiermeier, 'British universities set up European outposts as Brexit looms', Nature, 22 October 2018, https://www.nature.com/articles/d41586-018-07121-6, accessed 12 February 2019.

${ }^{27}$ University of Glasgow, University News, 'University Of Glasgow Signs Major European Partnership Agreement', 19 June 2018

https://www.gla.ac.uk/news/archiveofnews/2018/june/headline 592598 en.html, accessed 12 February 2019.

${ }^{28}$ University of Warwick, News and Events, 'University of Warwick launches major teaching and research collaboration with partners in Paris and Brussels', 28 March 2018

https://warwick.ac.uk/newsandevents/pressreleases/university of warwick launches major teaching and $r$ esearch collaboration with partners in paris and brussels1/, accessed 12 February 2019.

${ }^{29}$ University of Oxford, News and Events, 'Wide-ranging new research partnership with Berlin universities', 12 December 2017
}

http://www.ox.ac.uk/news/2017-12-12-wide-ranging-new-research-partnership-berlin-universities, accessed 12 February 2019. 
towards a more international student body, more teaching in English, and joint degree programmes for example.

As these final observations demonstrate, we are in highly speculative territory, not least because the type of Brexit (and future relationship) we will undergo is still so uncertain. However, the questions and possibilities raised here derive from real changes; while our forecasts may be uncertain, we can be sure that early career law academics will be launching into a rapidly changing academic environment. 